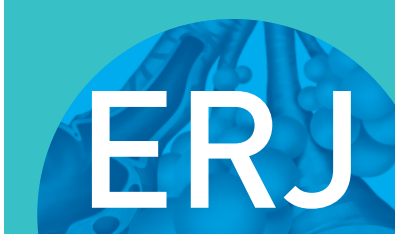

open research

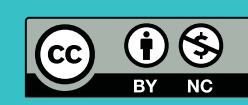

\section{Impact of comorbidities and delay in diagnosis in elderly patients with pulmonary hypertension}

\author{
Marylise Ginoux ${ }^{1}$, Ségolène Turquier ${ }^{2}$, Nader Chebib ${ }^{1}$, Jean-Charles Glerant ${ }^{2}$, \\ Julie Traclet ${ }^{1}$, François Philit ${ }^{1}$, Agathe Sénéchal ${ }^{1}$, Jean-François Mornex ${ }^{1,3}$ and \\ Vincent Cottin (10 ${ }^{1,3}$
}

Affiliations: ${ }^{1}$ Competence Center for Severe Pulmonary Hypertension, Reference Center for Rare Pulmonary Diseases, Dept of Respiratory Medicine, Hospices Civils de Lyon, Louis Pradel Hospital, Lyon, France. ${ }^{2}$ Dept of Respiratory Physiology, Hospices Civils de Lyon, Louis Pradel Hospital, Lyon, France. ${ }^{3}$ Université Lyon I, INRA, UMR754, Lyon, France.

Correspondence: Vincent Cottin, Centre de compétence de l'hypertension pulmonaire, Service de Pneumologie, Hospices Civils de Lyon, Hôpital Louis Pradel, 28 Avenue Doyen Lepine, 69677 Lyon, France. E-mail: vincent.cottindachu-lyon.fr

ABSTRACT Patient age at diagnosis of pulmonary hypertension is steadily increasing. The present study sought to analyse clinical characteristics, time to diagnosis and prognosis of pulmonary hypertension in elderly and very elderly patients.

A study was conducted in a French regional referral centre for pulmonary hypertension. All consecutive patients diagnosed with pre-capillary pulmonary hypertension were included and categorised according to age: $<65$ years (“young"), 65-74 years (“elderly") and $\geqslant 75$ years ("very elderly").

Over a 4-year period, 248 patients were included: 101 (40.7\%) were young, 82 (33.1\%) were elderly and $65(26.2 \%)$ were very elderly. The median age at diagnosis among the total population was 68 years. Compared with young patients, elderly and very elderly patients had a longer time to diagnosis $(7 \pm 48$, $9 \pm 21$ and $16 \pm 32$ months, respectively; $\mathrm{p}<0.001)$. Patients $\geqslant 75$ years also more often had group 4 pulmonary hypertension. The median overall survival was $46 \pm 1.4$ months, but was only $37 \pm 4.9$ months in elderly patients and $28 \pm 4.7$ months in very elderly patients. Survival from the first symptoms and survival adjusted to comorbidity was similar across age groups.

Patient age should be taken into account when diagnosing pulmonary hypertension as it is associated with a specific clinical profile and a worse prognosis. The difference in prognosis is likely to be related to a delay in diagnosis and a greater number of comorbidities.

$@$ ERSpublications

More than a quarter of patients diagnosed with pre-capillary pulmonary hypertension are older than 75 years; they have a poorer prognosis, likely related to a longer delay in diagnosis and a higher burden of comorbidities http://ow.ly/87FQ30m0WM7

Cite this article as: Ginoux M, Turquier S, Chebib N, et al. Impact of comorbidities and delay in diagnosis in elderly patients with pulmonary hypertension. ERJ Open Res 2018; 4: 00100-2018 [https://doi.org/10.1183/23120541.00100-2018].

Received: June 292018 | Accepted after revision: Sept 122018

Copyright $\odot$ ERS 2018. This article is open access and distributed under the terms of the Creative Commons Attribution Non-Commercial Licence 4.0. 


\section{Introduction}

Available demographic data for pulmonary hypertension come from national registries and focus on patients with pulmonary arterial hypertension (PAH) [1-7]. Scarce data are available in patients of all pulmonary hypertension subgroups [8].

The first registry published in 1987 reported a mean age of 36 years at diagnosis [1]; it is currently between 50 and 65 years [2-9]. In most published data, elderly patients ( $\geqslant 65$ years) with pulmonary hypertension exhibit specific clinical, aetiological and haemodynamic features [4-11]. Prognosis also seems to be worse in those $\geqslant 65$ years of age [6]. In clinical practice, specific management issues usually arise in patients $\geqslant 75$ years of age. The geriatric population more often has atypical clinical presentations, more comorbidities and the need for therapeutic adjustments. Although they represent an increasing proportion of patients, there are no data available for very elderly patients ( $\geqslant 75$ years).

Here, we present long-term survival data from patients with different pulmonary hypertension subtypes. We compared clinical characteristics, haemodynamic profiles and long-term survival of young ( $<65$ years), elderly (65-74 years) and very elderly ( $\geqslant 75$ years) patients. We also assessed the impact of age and time to diagnosis on their long-term survival.

\section{Patients and methods}

Data from a pulmonary hypertension regional centre cohort (Dept of Respiratory Medicine, Hospices Civils de Lyon, Louis Pradel Hospital, Lyon, France) were analysed. All consecutive patients referred to our centre for an initial assessment of pre-capillary pulmonary hypertension were included if data from right heart catheterisation at diagnosis showed mean pulmonary arterial pressure (mPAP) $\geqslant 25 \mathrm{mmHg}$, pulmonary vascular resistance $(\mathrm{PVR})>3$ Wood Units and pulmonary artery occlusion pressure (PAWP) $\leqslant 15 \mathrm{mmHg}$. Patients with pulmonary hypertension associated with respiratory disease were included if pulmonary hypertension was severe: $\mathrm{mPAP}$ at time of diagnosis $>35 \mathrm{mmHg}$ or cardiac index $<2.5 \mathrm{~L} \cdot \mathrm{min}^{-1} \cdot \mathrm{m}^{-2}[12,13]$

Elderly patients were defined as those aged $\geqslant 65$ years, in accordance with the threshold defined by the World Health Organization and used in earlier publications [6,9-11]. We chose a second threshold of $\geqslant 75$ years to define very elderly patients because it is the age used in France for admission to geriatric institutions [14]. Patients were thus divided into three groups according to their age at diagnosis: "young" patients were those aged <65 years, "elderly" patients were those aged 65-74 years, and "very elderly" patients were those aged $\geqslant 75$ years. Data were extracted from the electronic medical records of patients and from the national pulmonary hypertension register (for the Lyon centre), including all demographic, clinical, functional and haemodynamic characteristics. Diagnosis delay was defined as the time from onset of symptoms (usually dyspnoea) to the date of initial haemodynamic evaluation.

Categorical variables were described by frequency (number) and percentage. Quantitative variables were expressed as median and standard deviation. The assumption of normality of the distribution of quantitative variables was verified using the Kolmogorov-Smirnov test and verified graphically using a histogram. Categorical variables were compared by the Chi-squared test or Fisher's exact test, when the conditions for using the Chi-squared test were not met. Quantitative variables were compared between groups using the t-test, after verifying the equality of variances, when the distribution was normal, and the nonparametric Wilcoxon test (when it was less than three groups) or Kruskal-Wallis test (for comparison groups of three or more groups), when the distribution was not normal.

For survival analysis, time to the event was that between diagnosis and date of last known status or death (all cause). Overall survival between groups was compared by the Kaplan-Meier test and survival curves were produced using the log-rank test. The proportionality assumption of risk was verified; prognostic factors for death were determined using the Cox semiparametric model, initially using a univariate model, and then with a multivariate model that included the significant variables in the univariate analysis and relevant adjustment variables. A value of $\mathrm{p}<0.05$ was considered statistically significant. Analyses were performed using SPSS Statistics version 20 (IBM, Armonk, NY, USA).

\section{Results}

Over a 4-year period, 411 patients were referred to our department for an initial evaluation. 248 patients met the inclusion criteria (figure 1). 48 of these patients had no invasive re-evaluation and were therefore not included in the survival analyses.

The median \pm SD age at diagnosis was $68 \pm 13.7$ years; $33.1 \%(n=82)$ were elderly (median \pm SD age $70 \pm 2.8$ years) and $26.2 \%(n=65)$ were very elderly (median \pm SD age $79 \pm 3.7$ years) (table 1$)$. 


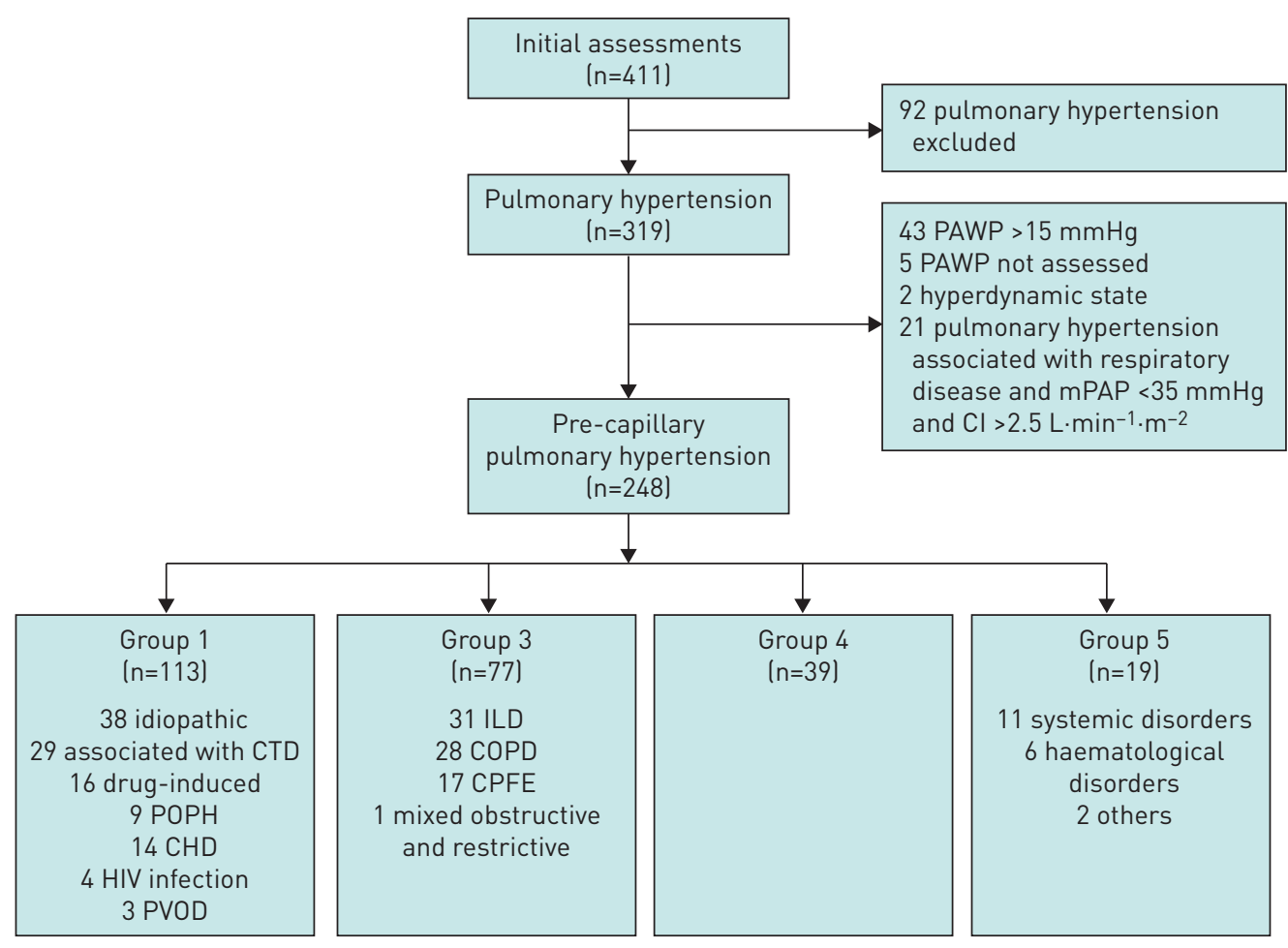

FIGURE 1 Selection of patients: 248 consecutive patients with newly diagnosed pre-capillary pulmonary hypertension were included in the study. PAWP: pulmonary arterial wedge pressure; mPAP: mean pulmonary arterial pressure; $\mathrm{Cl}$ : cardiac index; CTD: connective tissue disease; $\mathrm{POPH}$ : portopulmonary hypertension; CHD: congenital heart disease; PVOD: pulmonary veno-occlusive disease; ILD: interstitial lung disease; COPD: chronic obstructive pulmonary disease; CPFE: combined pulmonary fibrosis and emphysema.

\section{Clinical and functional characteristics}

There was a significant relationship between age and pulmonary hypertension aetiology $(\mathrm{p}<0.001)$. PAH (group 1) was diagnosed in $45.6 \%$ of patients and was the most common type of pulmonary hypertension in young patients (55.4\%). The elderly and very elderly patients more often had pulmonary hypertension associated with respiratory disease than young patients (group 3: $43.9 \%$ of elderly patients and $35.4 \%$ of

\section{TABLE 1 Clinical and functional characteristics of patients at initial assessment}

\begin{tabular}{|c|c|c|c|c|c|}
\hline & All & $\begin{array}{c}\text { Young } \\
\text { (<65 years) }\end{array}$ & $\begin{array}{c}\text { Elderly } \\
\text { (65-74 years) }\end{array}$ & $\begin{array}{l}\text { Very elderly } \\
(\geqslant 75 \text { years })\end{array}$ & p-value \\
\hline Patients & $248(100)$ & $101(40.7)$ & $82(33.1)$ & $65(26.2)$ & \\
\hline Age years & $68 \pm 13.7$ & $54 \pm 10.3$ & $70 \pm 2.8$ & $79 \pm 3.7$ & \\
\hline Female & $127(51.2)$ & 60 [59.4] & 31 (37.8) & $36(55.4)$ & 0.011 \\
\hline $\begin{array}{l}\text { Pulmonary hypertension } \\
\text { aetiological group }\end{array}$ & & & & & $<0.001$ \\
\hline Group 1 & $113(45.6)$ & $56(55.4)$ & 33 (40.2) & 24 (36.9) & \\
\hline Group 3 & $77(31.0)$ & 18 (17.8) & 36 (43.9) & $23(35.4)$ & \\
\hline Group 4 & $39(15.7)$ & $14(13.9)$ & $9(11.0)$ & $16(24.6)$ & \\
\hline Group 5 & $19(7.7)$ & $13(12.9)$ & $4(4.9)$ & $2(3.1)$ & \\
\hline Time to diagnosis months & $9 \pm 38$ & $7 \pm 48$ & $9 \pm 21$ & $16 \pm 32$ & 0.001 \\
\hline Functional class (NYHA) & & & & & 0.175 \\
\hline 1 & $11(4.5)$ & $5(5.0)$ & $5(6.2)$ & $1(1.6)$ & \\
\hline II & 82 (33.5) & 35 (35.0) & $29(35.8)$ & 18 (27.7) & \\
\hline III & $134(54)$ & $57(57.0)$ & $38(46.9)$ & $39(60.9)$ & \\
\hline IV & $18(7.3)$ & $3(3.0)$ & $9(11.1)$ & $6(9.4)$ & \\
\hline 6MWD m & 330 (127) & 355 (115) & 315 (117) & 210 (125) & $<0.001$ \\
\hline
\end{tabular}

Data are presented as $\mathrm{n}(\%)$ or median \pm SD, unless otherwise stated. NYHA: New York Heart Association; 6MWD: 6-min walk distance. 


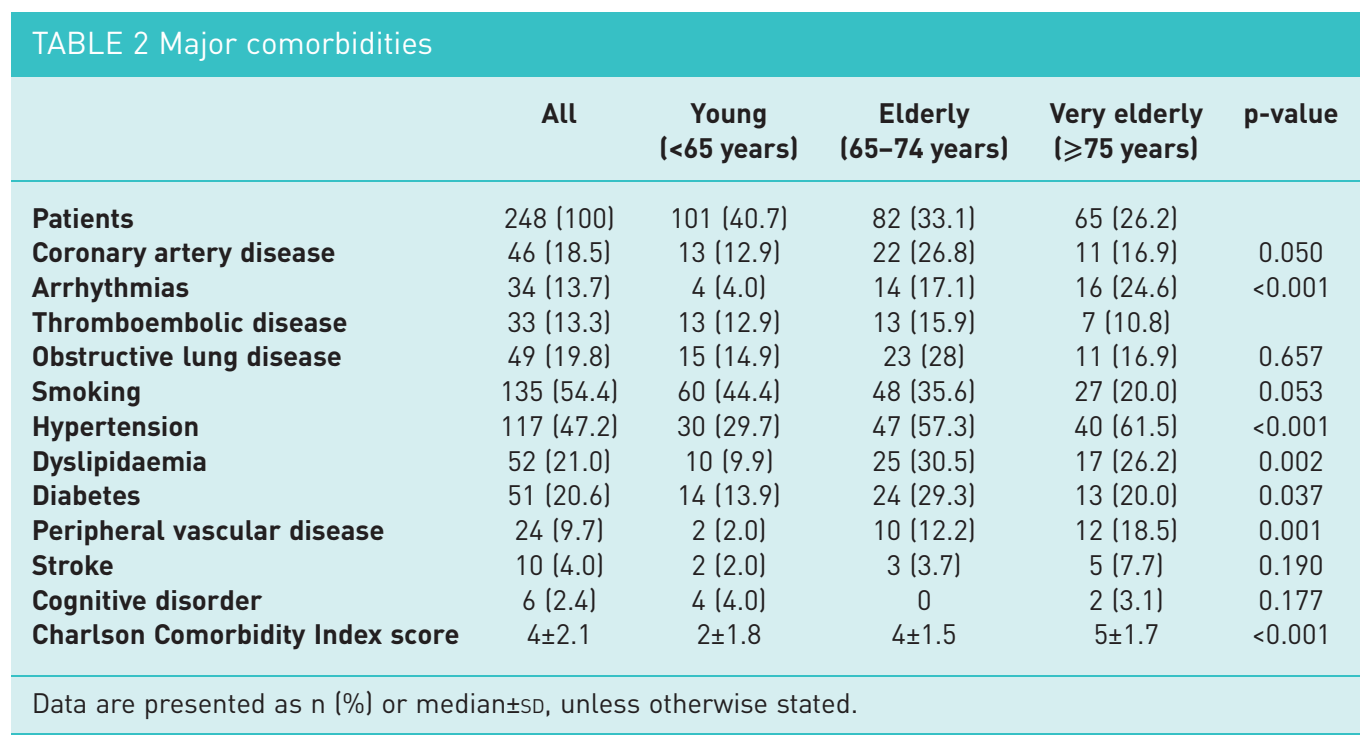

very elderly patients). In very elderly patients, nearly a quarter (24.6\%) had chronic thromboembolic pulmonary hypertension (group 4). Age was associated with a lower baseline 6-min walk distance (6MWD) $(\mathrm{p}<0.001)$, but the oldest patients were as often in functional class III or IV (New York Heart Association) as their younger counterparts $(\mathrm{p}=0.205)$. Very elderly patients had a higher prevalence of comorbidities: systemic arterial hypertension $(\mathrm{p}<0.001)$, coronary artery disease $(\mathrm{p}=0.05)$ and cardiac arrhythmias $(\mathrm{p}<0.001)$. The mean of the Charlson Comorbidity Index score increased according to age group $(\mathrm{p}<0.001)$ (tables 1 and 2$)$.

\section{Delay to diagnosis}

Very elderly patients had a longer delay in access to a regional referral centre for pulmonary hypertension than elderly and young patients. The mean \pm SD time to diagnosis was $7 \pm 48,9 \pm 21$ and $16 \pm 32$ months, respectively, for young, elderly and very elderly patients $(\mathrm{p}=0.001)$ (table 1$)$.

\section{Pulmonary haemodynamic features}

At the time of evaluation at a referral centre for pulmonary hypertension, pulmonary arterial pressure (systolic, mean and diastolic) and PVR were lower in elderly and very elderly patients than in young patients. PAWP was similar among age groups $(\mathrm{p}=0.755)$. The diastolic pressure gradient significantly decreased with age, but remained $>7 \mathrm{mmHg}$ in 241 out of 248 patients. We unexpectedly found that age $(\geqslant 75$ years) was associated with a lower cardiac index $(\mathrm{p}=0.004)$ (table 3$)$.

\section{TABLE 3 Initial haemodynamic data}

\begin{tabular}{|c|c|c|c|c|c|}
\hline & All & $\begin{array}{c}\text { Young } \\
\text { [<65 years) }\end{array}$ & $\begin{array}{c}\text { Elderly } \\
\text { (65-74 years) }\end{array}$ & $\begin{array}{l}\text { Very elderly } \\
1 \geqslant 75 \text { years })\end{array}$ & $p$-value \\
\hline Patients & 248 (100) & 101 (40.7) & 82 (33.1) & 65 (26.2) & \\
\hline sPAP $\mathrm{mmHg}$ & $64 \pm 17.6$ & $73 \pm 21.2$ & $61 \pm 12.7$ & $63 \pm 14.1$ & 0.001 \\
\hline mPAP mmHg & $39 \pm 11.2$ & $45 \pm 13.6$ & $37 \pm 6.7$ & $38 \pm 8.4$ & $<0.001$ \\
\hline dPAP $\mathrm{mmHg}$ & $25 \pm 8.8$ & $28 \pm 10.6$ & $24 \pm 5.9$ & $23 \pm 5.9$ & $<0.001$ \\
\hline PAWP $\mathrm{mmHg}$ & $8 \pm 3.3$ & $8 \pm 3.2$ & $8 \pm 3.36$ & $8 \pm 3.4$ & 0.755 \\
\hline RAP $\mathrm{mmHg}$ & $5 \pm 3.6$ & $6 \pm 3.7$ & $5 \pm 3.8$ & $6 \pm 3.4$ & 0.501 \\
\hline $\mathrm{CO} L \cdot \min ^{-1}$ & $4.56 \pm 1.4$ & $4.70 \pm 1.5$ & $4.83 \pm 1.2$ & $4.02 \pm 1.1$ & 0.001 \\
\hline $\mathrm{CI} \mathrm{L} \cdot \mathrm{min}^{-1} \cdot \mathrm{m}^{-2}$ & $2.52 \pm 0.7$ & $2.60 \pm 0.8$ & $2.59 \pm 0.7$ & $2.21 \pm 0.7$ & 0.004 \\
\hline PVR WU & $6.5 \pm 3.9$ & $7.3 \pm 4.7$ & $5.5 \pm 2.6$ & $6.7 \pm 3.4$ & 0.005 \\
\hline DPG $\mathrm{mmHg}$ & $17 \pm 8.8$ & $20 \pm 10.0$ & $16 \pm 6.8$ & $14 \pm 6.2$ & $<0.001$ \\
\hline
\end{tabular}

Data are presented as $\mathrm{n}(\%)$ or median \pm SD, unless otherwise stated. SPAP: systolic pulmonary arterial pressure; mPAP: mean pulmonary arterial pressure; dPAP: diastolic pulmonary arterial pressure; PAWP: pulmonary arterial wedge pressure; RAP: right atrial pressure; $\mathrm{CO}$ : cardiac output; $\mathrm{Cl}$ : cardiac index; PVR: pulmonary vascular resistance; WU: Wood Units; DPG: diastolic pressure gradient (dPAP-PAWP). 


\begin{tabular}{|c|c|c|c|c|c|}
\hline & All & $\begin{array}{c}\text { Young } \\
\text { (<65 years) }\end{array}$ & $\begin{array}{c}\text { Elderly } \\
\text { (65-74 years) }\end{array}$ & $\begin{array}{l}\text { Very elderly } \\
(\geqslant 75 \text { years })\end{array}$ & p-value \\
\hline Patients & $248(100)$ & $101(40.7)$ & $82(33.1)$ & $65(26.2)$ & \\
\hline Endothelin receptor antagonists & $116(46.8)$ & $59(58.4)$ & $28(34.1)$ & $29(44.6)$ & 0.005 \\
\hline Phosphodiesterase type 5 inhibitors & $122(49.2)$ & $46(44.6)$ & $43(52.4)$ & 33 (50.8) & 0.632 \\
\hline Epoprostenol & $14(5.6)$ & $11(10.9)$ & $1(1.2)$ & $2(3.1)$ & 0.014 \\
\hline Calcium channel blockers & 8 (3.2) & 3 (3) & $5(6.1)$ & & 0.120 \\
\hline Guanylate cyclase stimulators & $2(0.8)$ & & $1(1.2)$ & $1(1.5)$ & 0.515 \\
\hline Medication regimens & & & & & 0.010 \\
\hline Therapeutic abstention & $37(14.9)$ & $15(14.9)$ & $10(12.2)$ & $12(18.5)$ & \\
\hline Monotherapy & $164(66.1)$ & $58(57.4)$ & $65(79.3)$ & $41(63.1)$ & \\
\hline Dual therapy & $42(16.9)$ & $23(22.8)$ & $7(8.5)$ & 12 (18.5) & \\
\hline Triple therapy & $5(2.0)$ & $5(5.0)$ & & & \\
\hline
\end{tabular}

\section{Initial therapeutic management}

$85.1 \%$ of the patients had been treated. 37 patients $(14.9 \%)$ had not been treated because either they had a thromboendarterectomy $(n=12)$ or because they had too many comorbidities $(n=25)$.

The choice of the medications and their combinations differed between age groups $(p=0.010)$. Younger patients more often received endothelin receptor antagonists, epoprostenol and combined therapies than older patients (table 4). This difference in therapeutic management probably contributed to the difference in outcomes among the age groups.

\section{Long-term survival}

Overall 1-, 2- and 3-year survival was $81 \%, 71 \%$ and $57 \%$, respectively. Survival differed significantly between age groups. Survival of very elderly patients was only $65 \%, 59 \%$ and $40 \%$ at 1, 2 and 3 years $(\mathrm{p}<0.001)$ (figure $2 \mathrm{a})$. The median survival was not reached in young patients and decreased with age in the two groups of older patients (elderly $37 \pm 4.9$ months and very elderly $28 \pm 4.7$ months; $\mathrm{p}<0.001$ ).

When survival was considered from the date of the first symptoms or was adjusted to the Charlson Comorbidity Index score, no differences were found between age groups $(p=0.237$ and $p=0.343$, respectively) (figure $2 \mathrm{~b}$ and $\mathrm{c}$ ).

\section{Risk factors for death}

According to univariate analysis, male sex, aetiological group 3 pulmonary hypertension, a 6MWD $<210 \mathrm{~m}$ and a history of COPD, stroke or cognitive disorders were associated with higher mortality in very elderly patients.

\section{Discussion}

The overall long-term survival (57\% at 3 years) was lower in patients in our study than observed in previous registries [2-8]. This finding could be explained by the significant number of very elderly patients included. Over half of patients diagnosed with a pre-capillary pulmonary hypertension were aged $\geqslant 65$ years and a quarter where even aged $\geqslant 75$ years. This poorer prognosis could also be explained by a high prevalence of patients with group 3 pulmonary hypertension, who are known to have a worse prognosis [12].

Unlike most previous reports, the present study included patients in all pre-capillary pulmonary hypertension subgroups. There were more patients with pulmonary hypertension due to chronic respiratory disease (group 3 pulmonary hypertension) or chronic thromboembolic disease (group 4 pulmonary hypertension) in the "elderly" and "very elderly" groups than in the "young" group. Nearly a quarter of very elderly patients had chronic thromboembolic pulmonary hypertension, which is likely to be explained by the increase in the incidence of pulmonary embolism with age (1.3 per 1000 habitants per year between 65 and 69 years; up to 2.8 per 1000 habitants per year between 85 and 89 years) [15].

We have shown that pulmonary hypertension is often initially misdiagnosed in very elderly patients, who were probably diagnosed at a later stage of the disease. The cardiac index has usually been reported to be age independent $[2,4,6,10,11]$. In this study, mean cardiac output and cardiac index values were lower 


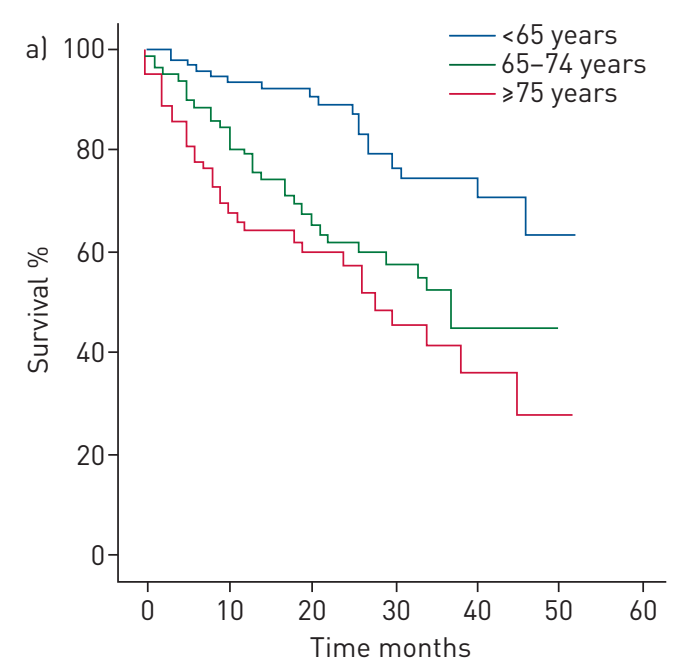

\begin{tabular}{lcccc}
\hline & 12 & 24 & 36 & Deaths \\
& months & months & $\begin{array}{c}\text { months } \\
n\end{array}$ \\
\hline All & $248(81)$ & $157(71)$ & $96(57)$ & 82 \\
$<65$ years & $101(93)$ & $71(89)$ & $48(74)$ & 18 \\
65-74 years & $82(80)$ & $52(62)$ & $28(52)$ & 32 \\
$\geqslant 75$ years & $65(65)$ & $34(59)$ & $20(40)$ & 32 \\
\hline
\end{tabular}
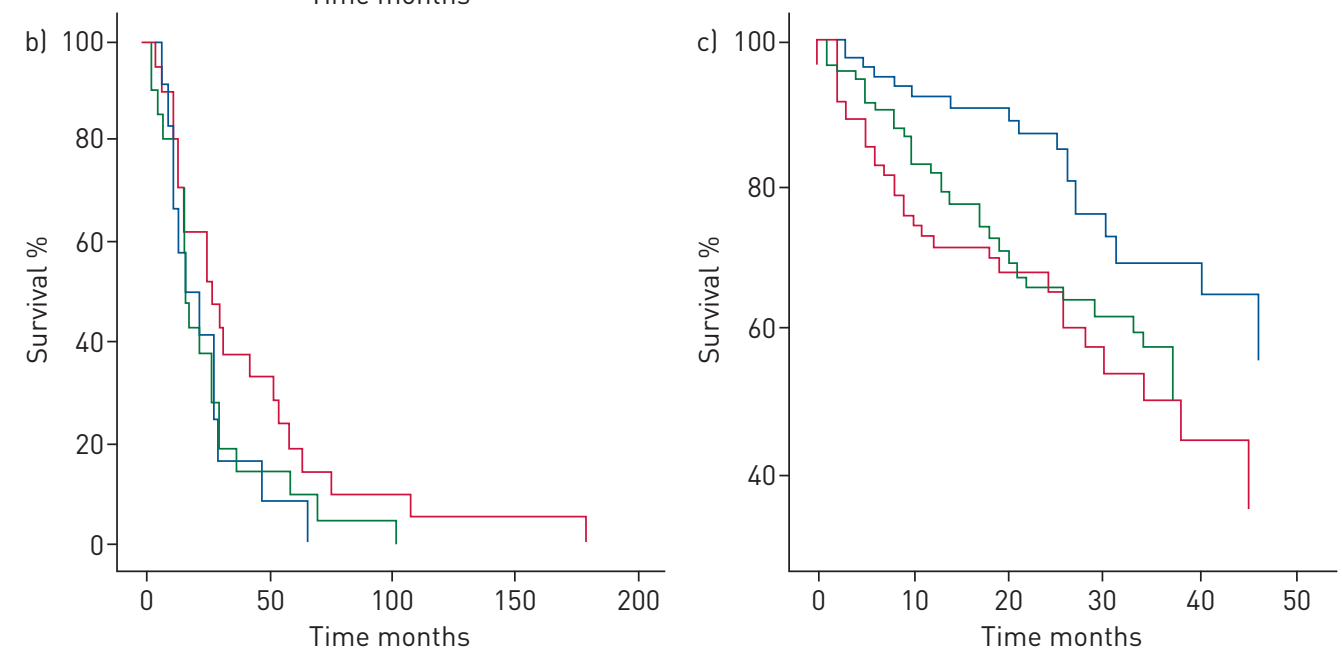

FIGURE 2 Kaplan-Meier curves of long-term survival in young $(<65$ years), elderly (65-74 years) and very elderly ( $\geqslant 75$ years) patients with pre-capillary pulmonary hypertension. a) Observed survival difference was statistically significant between age groups $(p<0.001)$. The table presents observed survival at 12,24 and 36 months (n (\%)), and number of deaths by age group. b) Observed survival difference from the first symptoms was not statistically significant between age groups ( $p=0.237$. c) Observed survival difference after adjustment with the Charlson Comorbidity Index score was also not statistically significant between age groups $(p=0.064)$.

in very elderly compared with younger patients. We should therefore wonder if this impaired ventricular function had contributed to a worse outcome in very elderly patients.

The significantly delayed access to a referral centre for pulmonary hypertension, which partly explained their poorer prognosis, is not the single cause of excess mortality in elderly and very elderly patients. This study was an overall survival analysis including all-cause mortality and did not find significant differences in the causes of death according to age. However, the weight of comorbidities seemed to be predominant in the survival of elderly patients. Associated lung disease and cardiovascular comorbidities were more frequent in elderly patients, and might be a leading cause of death. The Charlson Comorbidity Index, used to assess the competitive comorbidities, correlates with patient survival and has been approved for the treatment of geriatric patients [16-18]. After adjusting on the Charlson Comorbidity Index, survival was comparable across the three age groups. Moreover, in patients aged $\geqslant 75$ years, only a history of COPD and stroke were independent predictors of mortality.

There were several limitations to our study. First, the analysis was retrospective, but most of the data were nevertheless collected prospectively in a national registry at the time of each hospitalisation. It was a single-centre study, but included a relatively large cohort of patients all seen in a tertiary referral department for pulmonary vascular diseases. The study population was heterogeneous due to the inclusion of all pre-capillary pulmonary hypertension causes and was therefore representative of the population seen 
in clinical practice. Finally, being those with the most severe comorbidities or cognitive problems, very elderly patients may not have been referred for evaluation.

\section{Conclusions}

More than a quarter of patients diagnosed with pre-capillary pulmonary hypertension are aged $\geqslant 75$ years. The age of the patients should be taken into account in diagnosing pulmonary hypertension, as it is associated with a specific clinical profile: a longer time to diagnosis and therefore a delayed access to a referral centre for pulmonary hypertension, a high proportion of group 3 and 4 pulmonary hypertension, a higher rate of comorbidities, and lower cardiac index. The long-term survival is worse for elderly and very elderly patients than for their younger counterparts. This difference is likely to be related to a longer delay in diagnosis and a higher burden of comorbidities.

Conflict of interest: M. Ginoux has nothing to disclose. S. Turquier has nothing to disclose. N. Chebib has nothing to disclose. J.C. Glerant has nothing to disclose. J. Traclet has nothing to disclose. F. Philit has nothing to disclose. A. Sénéchal has nothing to disclose. J.F. Mornex reports receiving consulting fees and research grants from LFB Biomédicaments, CSL Behring, and travel and meeting support and lecture fees from Actelion, Pierre Fabre, Boehringer Ingelheim, Pfizer, GSK, Chiesi, Novartis, Almirall, MSD and Bioprojet, outside the submitted work. V. Cottin reports personal fees from Actelion, Bayer, Biogen Idec, Boehringer Ingelheim, Gilead, GSK, Intermune, Lilly, Novartis, Pfizer, Roche, Sanofi, and grants from Actelion, Boehringer Ingelheim, GSK, Pfizer and Roche, outside the submitted work.

\section{References}

1 Rich S, Dantzker DR, Ayres SM, et al. Primary pulmonary hypertension. A national prospective study. Ann Intern Med 1987; 107: 216-223.

2 Badesch DB, Raskob GE, Elliott CG, et al. Pulmonary arterial hypertension: baseline characteristics from the REVEAL Registry. Chest 2010; 137: 376-387.

3 Humbert M, Sitbon O, Chaouat A, et al. Pulmonary arterial hypertension in France: results from a national registry. Am J Respir Crit Care Med 2006; 173: 1023-1030.

4 Ling Y, Johnson MK, Kiely DG, et al. Changing demographics, epidemiology, and survival of incident pulmonary arterial hypertension: results from the pulmonary hypertension registry of the United Kingdom and Ireland. Am J Respir Crit Care Med 2012; 186: 790-796.

5 Hurdman J, Condliffe R, Elliot CA, et al. ASPIRE registry: Assessing the Spectrum of Pulmonary hypertension Identified at a REferral centre. Eur Respir J 2012; 39: 945-955.

6 Hoeper MM, Huscher D, Ghofrani HA, et al. Elderly patients diagnosed with idiopathic pulmonary arterial hypertension: results from the COMPERA registry. Int J Cardiol 2013; 168: 871-880.

7 McGoon MD, Benza RL, Escribano-Subias P, et al. Pulmonary arterial hypertension: epidemiology and registries. J Am Coll Cardiol 2013; 62: 25 Suppl., D51-D59.

8 Gall H, Felix JF, Schneck FK, et al. The Giessen Pulmonary Hypertension Registry: survival in pulmonary hypertension subgroups. J Heart Lung Transplant 2017; 36: 957-967.

9 Shapiro BP, McGoon MD, Redfield MM. Unexplained pulmonary hypertension in elderly patients. Chest 2007; 131: 94-100.

10 Frachon I, Barnier A, Jobic Y, et al. Hypertension arterielle pulmonaire du sujet age. La cohorte d'un centre regional. [Pulmonary arterial hypertension in the elderly subject.] Rev Mal Respir 2010; 27: 30-36.

11 Shimony A, Fox BD, Afilalo J, et al. Pulmonary arterial hypertension in the elderly - clinical characteristics and long-term survival. Lung 2012; 190: 645-649.

12 Seeger W, Adir Y, Barberà JA, et al. Pulmonary hypertension in chronic lung diseases. J Am Coll Cardiol 2013; 62: 25 Suppl., D109-D116.

13 Galié N, Humbert M, Vachiery JL, et al. 2015 ESC/ERS guidelines for the diagnosis and treatment of pulmonary hypertension. Eur Respir J 2015; 46: 903-975.

14 Dept of Hospitalisation and the Organization of Care. Circular DHOS/02 No. 2007-117 of March 28, 2007 on the geriatric care sector. SANT4 Official Bulletin 2007-4: Announcement 58. 2007. http://social-sante.gouv.fr/fichiers/ bo/2007/07-04/a0040058.htm Date last accessed: August 29, 2016.

15 Kniffin WD, Baron JA, Barrett J, et al. The epidemiology of diagnosed pulmonary embolism and deep venous thrombosis in the elderly. Arch Intern Med 1994; 154: 861-866.

16 Charlson ME, Pompei P, Ales KL, et al. A new method of classifying prognostic comorbidity in longitudinal studies: development and validation. J Chronic Dis 1987; 40: 373-383.

17 Frenkel WJ, Jongerius EJ, Mandjes-van Uitert MJ, et al. Validation of the Charlson Comorbidity Index in acutely hospitalized elderly adults: a prospective cohort study. J Am Geriatr Soc 2014; 62: 342-346.

18 Librero J, Peiró S, Ordiñana R. Chronic comorbidity and outcomes of hospital care: length of stay, mortality, and readmission at 30 and 365 days. J Clin Epidemiol 1999; 52: 171-179. 